\title{
ARTICULAR CHANGES ASSOCIATED WITH A FLEXION DEFORMITY IN RHEUMATOID AND OSTEOARTHRITIC KNEES
}

\author{
W. WAUGH, G. NEWTON, M. TEW
}

\begin{abstract}
In a consecutive series of 87 operations for knee replacement prospective observations were made of the pattern of articular destruction in the form of a triangle of erosion or osteophyte formation, which is seen on the medial femoral condyle, sometimes with an associated strip on the lateral femoral condyle. These areas represent the surfaces which are normally in contact with the anterior horns of the menisci when the knee is fully extended. The lesions in question were found only in association with a flexion contracture in 84 out of the 87 cases.
\end{abstract}

During the course of more than 250 knee replacements and synovectomies, one of us (WW) had observed an anatomical pattern in the loss of articular cartilage over the lower end of the femur. In many cases an area of destruction, due either to erosion or osteophyte formation could be recognised as a triangle on the medial femoral condyle at the junction of its tibial and trochlear surfaces. A corresponding lesion, but in the form of a strip, was sometimes present at a similar level on the lateral femoral condyle. The sites of these two lesions are shown diagrammatically in Figure 1.

These lesions were seen at a relatively early stage during synovectomy when the triangular area might be covered by pannus from the synovial surface. When this material was removed the lesion on the underlying

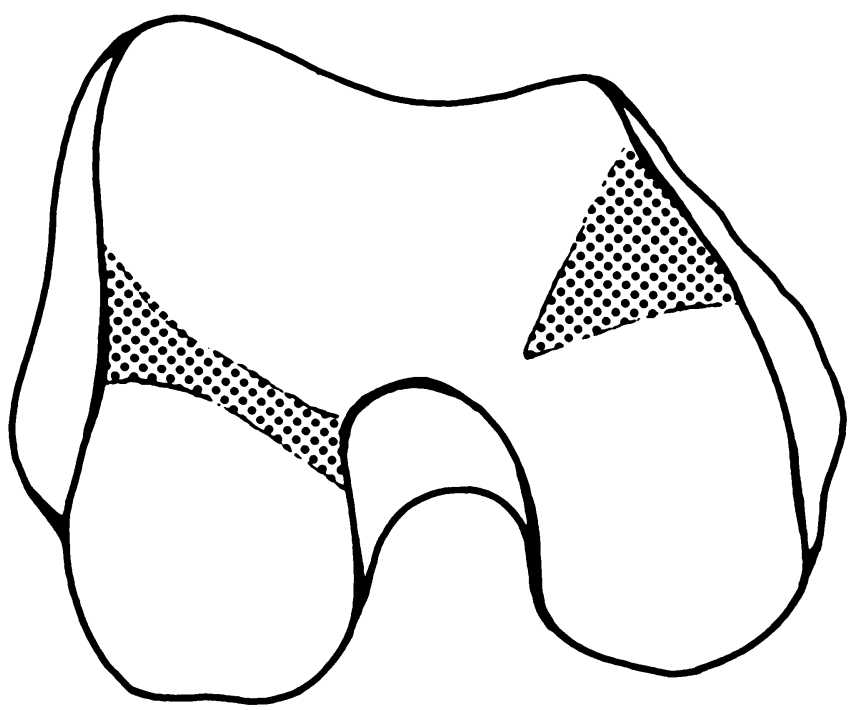

Fig. 1

This diagram shows the site of the triangle on the medial femoral condyle and the strip on the lateral femoral condyle. These are areas in which pannus infiltration, erosion or osteophyte formation are frequently seen in rheumatoid and osteoarthritic knees. articular cartilage was revealed as a clearly defined triangle (Fig. 2). Another example of pannus over the medial triangle and loss of articular cartilage in the lateral strip is shown in Figure 3. A combination of pannus and osteophyte formation might be present (Fig. 4). In primary osteoarthritis, the triangle might be occupied by an osteophyte (Fig. 5) which had blocked extension.

These lesions, briefly described and illustrated, represent a changing pathological process in which destruction of articular cartilage will eventually become so extensive that the triangular and linear lesions are no longer distinguishable.

\section{THE HYPOTHESIS}

The sites of erosion of articular cartilage have been reported (Chaplin 1971), but no explanation for this particular pattern has previously been suggested. There is, however, an obvious similarity between these areas and the two shallow depressions on the articular surface which some textbooks of anatomy show in illustrations of the lower end of the femur. These depressions are described (Gray's Anatomy 1973) as being the areas of contact which the anterior ends of the menisci make with the femoral condyles when the knee is fully extended. The two areas are clearly seen in a detailed anatomical drawing (Fig. 6): the base of the triangle on the medial femoral condyle is where the lateral rotation occurs as the knee finally "locks home".

Since the lesions arise in those areas which have no apposing articular surface when the knee cannot be fully extended, it seemed reasonable to suppose that this type of erosion or osteophyte formation would be likely to accompany a flexion contracture. Salter and McNeil (1965) demonstrated that degenerative changes developed when articular cartilage was no longer in contact with an apposing surface. Such areas may

Professor W. Waugh, MChir, FRCS Department of Surgery (Orthopaedic and Accident Surgery), Medical School, Mrs M. Tew, MA, Research Associate Queen's Medical Centre, Clifton Boulevard, Nottingham NG7 2UH, England. G. Newton, FRCS, Bretby Hall Orthopaedic Hospital, Bretby, nr Burton on Trent, Staffordshire, England.

Requests for reprints should be sent to Professor Waugh. 


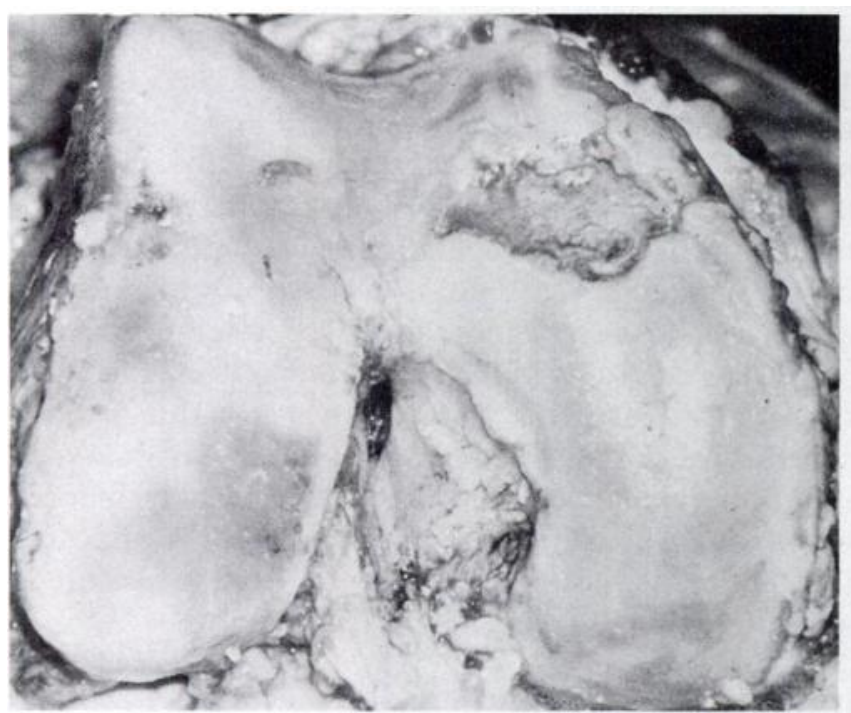

Fig. 2

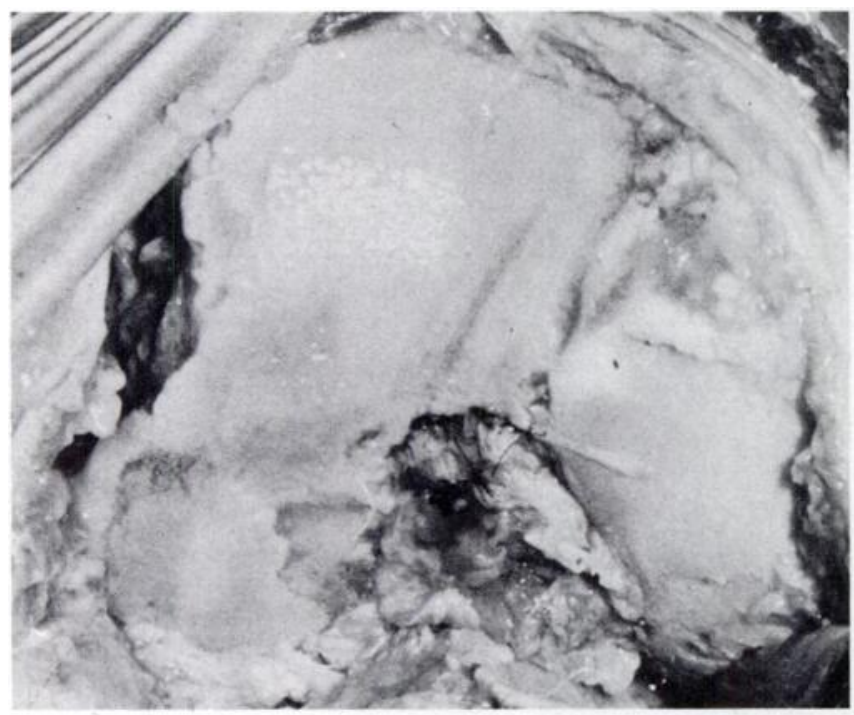

Fig. 4

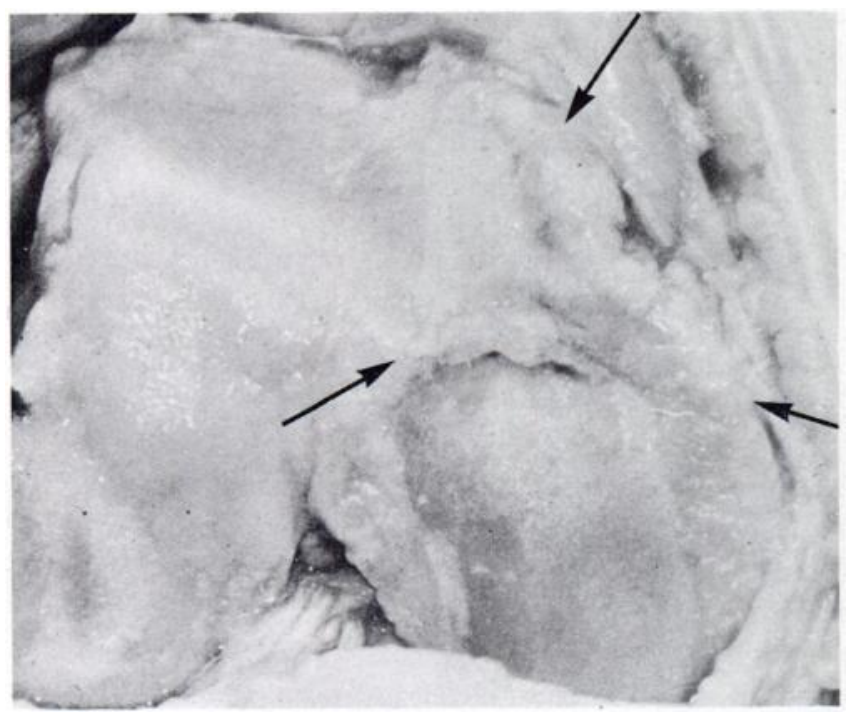

Fig. 5

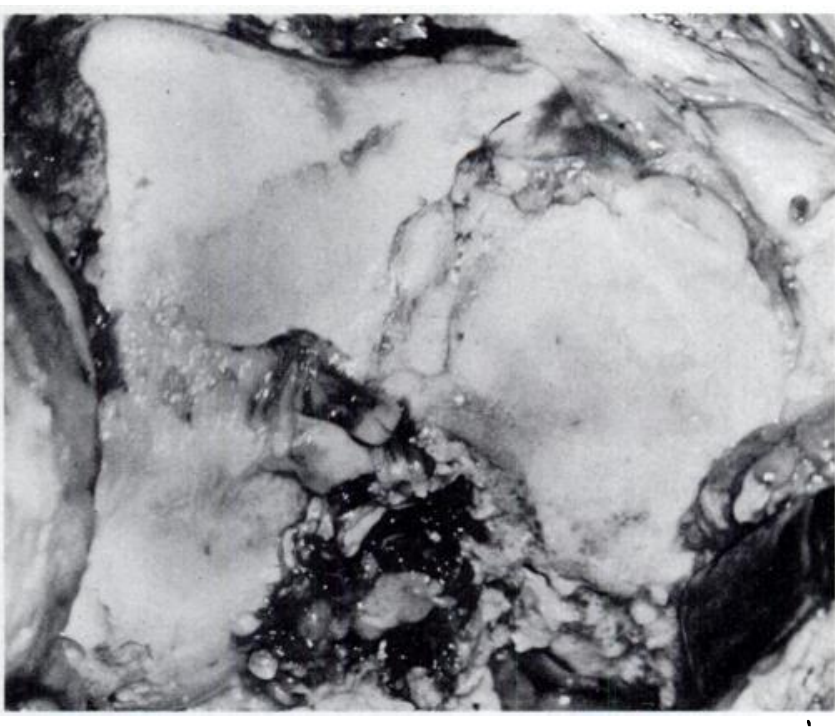

Fig. 3

Figure 2-This photograph of the lower end of the femur was taken after a synovectomy had been carried out. Pannus had previously covered the clearly defined area of loss of articular cartilage on the medial femoral condyle. Figure 3-There is pannus infiltration over the medial triangle and destruction of articular cartilage in the lateral strip. This knee also shows an intense intercondylar synovitis. Figure 4-In this knee there is infiltration of pannus and early osteophyte formation in the medial triangle. Figure 5-The arrows indicate a triangular osteophyte seen in a knee with primary osteoarthritis.

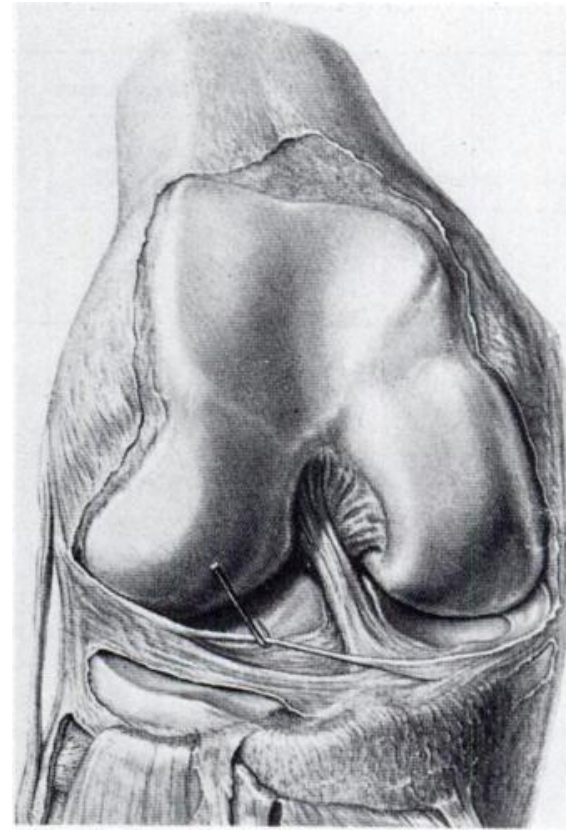

Fig. 6

This anatomical drawing of the end of a femur clearly shows the triangle on the medial condyle and the lateral strip on the lateral condyle. (From: Pernkopf E. Topographische Anatomie Dis Menschen. Munich: Urban and Schwarzenberg, 1980, vol 2.) 
become infiltrated by synovial pannus when a flexion contracture is present. This hypothesis, which would explain the site of the lesions, needed to be tested by prospective observations of the findings at operation.

\section{METHOD}

A standard form was prepared on which the surgeon recorded the patient's age and the diagnosis; the main areas of erosion of the articular cartilage or of osteophyte formation were shaded onto an outline of the lower end of the femur; and the extent (or absence) of any flexion contracture was recorded to the nearest 10 degrees.

The forms were completed in a consecutive series of 87 unselected knee replacements which were carried out at Harlow Wood Orthopaedic Hospital (39 operations) and Bretby Orthopaedic Hospital (48 operations) between December 1977 and October 1978. Rheumatoid arthritis, alone or with osteoarthritis, was the diagnosis in 54 cases and osteoarthritis alone in 31 cases (the diagnosis was not

\section{RESULTS}

Erosion or osteophyte formation in the triangle on the medial femoral condyle was observed in 45 of the 55 knees which had a flexion contracture of 10 degrees or more, but was not observed in 29 of the 32 knees which extended fully before operation. This difference was highly significant $(P<0.001)$. It was highly significant also in each of the series considered separately (Table I).

The strip lesion in the lateral femoral condyle was observed in 25 of the 55 knees which had a flexion contracture of 10 degrees or more, but was not observed in 31 of the 32 knees which extended fully before operation. This difference also is highly significant $(P<0.001)$. It is significant in each series considered separately $(P<0.005)$ (Table II).

Table I. Relation between the lesion in the medial triangle and flexion contracture

\begin{tabular}{|c|c|c|c|c|c|c|c|c|c|}
\hline \multirow[b]{2}{*}{ Flexion contracture } & \multicolumn{3}{|c|}{ Combined series } & \multicolumn{3}{|c|}{ Bretby series } & \multicolumn{3}{|c|}{ Harlow Wood series } \\
\hline & $\begin{array}{l}\text { Lesion } \\
\text { present }\end{array}$ & $\begin{array}{l}\text { Lesion } \\
\text { absent }\end{array}$ & Total & $\begin{array}{l}\text { Lesion } \\
\text { present }\end{array}$ & $\begin{array}{l}\text { Lesion } \\
\text { absent }\end{array}$ & Total & $\begin{array}{l}\text { Lesion } \\
\text { present }\end{array}$ & $\begin{array}{l}\text { Lesion } \\
\text { absent }\end{array}$ & Total \\
\hline Present & 45 & 10 & 55 & 18 & 8 & 26 & 27 & 2 & 29 \\
\hline Absent & 3 & 29 & 32 & 2 & 20 & 22 & 1 & 9 & 10 \\
\hline Total & 48 & 39 & 87 & 20 & 28 & 48 & 28 & 11 & 39 \\
\hline Level of significance & \multicolumn{3}{|c|}{$P<0.001$} & \multicolumn{3}{|c|}{$P<0.001$} & \multicolumn{3}{|c|}{$P<0.001$} \\
\hline
\end{tabular}

Table II. Relation between the lesion in the lateral strip and flexion contracture

\begin{tabular}{|c|c|c|c|c|c|c|c|c|c|}
\hline \multirow[b]{2}{*}{ Fiexion contracture } & \multicolumn{3}{|c|}{ Comblned series } & \multicolumn{3}{|c|}{ Bretby series } & \multicolumn{3}{|c|}{ Harlow Wood series } \\
\hline & $\begin{array}{l}\text { Lesion } \\
\text { present }\end{array}$ & $\begin{array}{l}\text { Lesion } \\
\text { absent }\end{array}$ & Total & $\begin{array}{l}\text { Lesion } \\
\text { present }\end{array}$ & $\begin{array}{l}\text { Lesion } \\
\text { absent }\end{array}$ & Total & $\begin{array}{l}\text { Lesion } \\
\text { present }\end{array}$ & $\begin{array}{l}\text { Lesion } \\
\text { absent }\end{array}$ & Total \\
\hline Present & 25 & 30 & 55 & 9 & 17 & 26 & 16 & 13 & 29 \\
\hline Absent & 1 & 31 & 32 & 1 & 21 & 22 & 0 & 10 & 10 \\
\hline Total & 26 & 61 & 87 & 10 & 38 & 48 & 16 & 23 & 39 \\
\hline Level of significance & \multicolumn{3}{|c|}{$P<0.001$} & \multicolumn{3}{|c|}{$P<0.005$} & \multicolumn{3}{|c|}{$P<0.005$} \\
\hline
\end{tabular}

recorded for two knees); the proportion of rheumatoid knees was greater at Bretby, but not significantly so. Fifty-five knees had a flexion contracture of 10 degrees or more: the proportion was greater at Harlow Wood, but again not significantly so. Throughout the analysis statistical significance was determined by the chi-squared test.

When the review had been completed, the diagrams were assessed by two observers (WW and MT) who did not know whether a flexion contracture had been recorded as being present or absent. The described lesion was considered to be present if there was evidence of erosion, infiltration of pannus, degeneration or osteophyte formation in the triangular area on the medial condyle or in the strip on the lateral condyle. No attempt was made to differentiate between the types of pathological lesion in the analysis. This was because definition was often difficult, since infiltration of pannus, erosion and early osteophyte formation might be present together at the same site.
There was no significant association between the occurrence of either lesion and the age of the patient, the diagnosis or the degree of flexion contracture.

\section{DISCUSSION}

There is, therefore, a highly significant association between both the triangular lesion on the medial femoral condyle and the strip lesion on the lateral femoral condyle and a flexion contracture. These lesions are rarely seen when the knee can be fully extended. The proof involved interpretation of findings recorded after operation. The natural bias of one of us (WW) was in 
part countered by including the findings of a second surgeon (GN), who had not been involved in making the original observation or the hypothesis. In a further attempt to diminish bias the diagrams were classified without knowledge of whether or not flexion contracture was present. The results in both series were convincing on statistical analysis and supported the hypothesis.

That the lesions were not always present when there was a flexion contracture may be partly explained by the fact that in many of these knees the contracture was severe, suggesting that it might have been of long duration, so that the extensive destruction of articular cartilage had obscured the initial lesions. On the other hand, the lesion should, in theory, always have been absent when the knee could be fully extended. In fact, the triangular lesion was noted in three such knees, in one of which the strip lesion was also noted. In all three cases the triangular lesion was recorded as "small" or "slight" and may have been associated with a flexion contracture of up to five degrees, which was graded as absent. Alternatively, the findings at operation may have been interpreted incorrectly.

We have not attempted to describe the basic mechanisms which produce destruction of articular cartilage or osteophyte formation; nor have the possible causes of a flexion contracture been discussed. Nonetheless, the review of our operative findings demonstrates that infiltration of pannus, erosion and osteophyte formation occur in a triangle on the medial femoral condyle and in a strip on the lateral femoral condyle when a flexion contracture is present. It seems reasonable to suppose that the contracture precedes the articular lesion, and this means that any knee which does not extend fully is likely to develop pathological changes in the areas described. Other mechanisms must operate, but the hypothesis put forward supports the view that a flexion contracture should always be treated as soon as possible and full extension restored by whatever means are necessary.

\section{REFERENCES}

Chaplin DM. The pattern of bone and cartilage damage in the rheumatoid knee. J Bone Joint Surg [Br] 1971;53-B:711-7. Gray's Anatomy. 35th ed. Edinburgh: Longman, 1973;362.

Salter RB, McNeil R. Pathological changes in articular cartilage secondary to persistent joint deformity. J Bone Joint Surg [Br] $1965 ; 47-B: 185-6$ 